\title{
Molecular Properties of Fatty Acid Mixtures Estimated by Online Time-Domain NMR
}

\author{
Ekaterina Nikolskaya ${ }^{1}$ (D) $\cdot$ Yrjö Hiltunen $^{1}$
}

Received: 24 October 2017 / Revised: 11 July 2018 / Published online: 31 July 2018

(c) The Author(s) 2018

\begin{abstract}
An approach based on time-domain nuclear magnetic resonance (TD-NMR) enables the estimation of the molecular properties of fatty acid mixtures-kinematic viscosity $(\mu)$, heating value $(\delta)$, cetane number $(\mathrm{CN})$, and carbon chain length $(\mathrm{CL})$. In this approach, the ${ }^{1} \mathrm{H}$ NMR spin-spin relaxation rates $R_{2}$ or times $T_{2}$ were used to determine these molecular properties. Online monitoring of the $\mu, \delta, \mathrm{CN}$, and CL of fatty acid mixtures was performed using an online TD-NMR system that had been modified for flowing samples. The presented results show the potential of TD-NMR for online quality control during the production of liquid fuels.
\end{abstract}

\section{Introduction}

The determination of liquid fuel quality parameters has become more important because of stricter environmental legislation. The main properties of liquid fuels, such as the carbon chain length (CL), viscosity $(\mu)$, high heating value (heat of combustion) $(\delta)$, cetane number $(\mathrm{CN})$, density, pour point, and cloud point $[1,2]$, change during processing. To control the production of petroleum fractions or biofuels, which are alternatives to traditional fossil fuels [2-4], the changes in their molecular properties should be tracked. Quality parameters of liquid fuels are typically determined by international standards, such as ASTM D445-06, ASTM D240-02, and ASTM 613-05 for the estimation of the $\mu, \delta$ and $\mathrm{CN}$ of biodiesel [5]. However, the standard measurement methods for liquid fuel parameters are time-consuming and labourious; thus, they are difficult to apply to online process control.

High-resolution nuclear magnetic resonance (NMR) spectroscopy is a standard technique for molecular structure and molecular mobility investigations of different

Ekaterina Nikolskaya

ekaterina.nikolskaya@xamk.fi

Yrjö Hiltunen

yrjo.hiltunen@xamk.fi

1 FiberLaboratory, South-Eastern Finland University of Applied Sciences, Vipusenkatu 10, 57200 Savonlinna, Finland 
substances and is well established in the chemical analysis of liquid fuels [3, 6-10]. However, traditional high-resolution NMR spectrometers are hardly applied to industrial process control due to their open magnetic field, large size and high price and the required cryogen use. Recently developed low-field benchtop spectrometers with permanent magnets (up to $2 \mathrm{~T}$ ) are less expensive and more compact and provide sufficient accuracy for chemical analysis, making them competitive with traditional high-resolution spectrometers [11, 12]. A compact NMR spectrometer was applied to the determination of several quality parameters of diesel fuel in the paper by Killner et al. [13].

Time-domain nuclear magnetic resonance (TD-NMR) is a versatile analysis tool for determining the chemical and physical properties of a wide variety of materials with a constantly growing area of application, including laboratory and industrial analyses $[14,15]$, although TD-NMR does not give the same level of detail of chemical structures as high-resolution NMR spectroscopy. However, TD-NMR has proven usable in industrial applications due to its mobility, low price, robustness, non-destructive analysis, and lack of sample preparation $[11,15,16]$. Furthermore, online process monitoring by NMR is also an increasingly used technique $[11,12$, 17]. In one study [18], the TD-NMR technique was applied to the online determination of metal ion precipitation in mine water and was subsequently tested in a mine environment. The promising results obtained in this study illustrate the potential of TD-NMR for real process control.

TD-NMR has been proposed as an alternative technique to predict several liquid fuel properties, such as the cetane index, density, flash point, temperature to achieve $50 \%$ distillation of a sample (T50) [19], biodiesel content of diesel fuel [14], viscosity, refractive index, American Petroleum Institute (API) gravity [20], total acid number [20,21], and sulphur content [21] in petroleum fractions. The fatty acid composition, viscosity, $\mathrm{CN}$, and iodine content of different intact oilseeds were estimated using ${ }^{1} \mathrm{H}$ transverse relaxation time $T_{2}$ data combined with chemometric techniques [22]. The transesterification reaction of oil was monitored in situ by measuring the transverse relaxation decay in the work by Cabeça et al. [23]. Moreover, TD-NMR can be used to determine the CLs of fatty acid mixtures [24]. Because the CL strongly affects the $\mu, \delta$, and $\mathrm{CN}$ of liquid fuels [2, 5], TD-NMR could be applied to evaluate the quality parameters of liquid fuels.

In the current work, a general dependence between the molecular properties of fatty acid mixtures and the spin-spin relaxation times or rates measured by TDNMR is presented. The possibility of using online TD-NMR for the rapid measurement of several quality parameters of liquid fuels, such as the $\mu, \delta, \mathrm{CN}$ and CL, is shown.

\section{Materials and Methods}

\subsection{Samples}

The properties of several fatty acids methyl esters (FAMEs), which are the main components of liquid biofuels, are shown in Table 1. These properties are used 
Table 1 Data on the $\mu, \delta, \mathrm{CN}$, and CL of FAMEs determined experimentally in Ref. [25] and estimated using Eqs. (1-3)

\begin{tabular}{lllllc}
\hline $\begin{array}{l}\text { Fatty acid cor- } \\
\text { responded to a } \\
\text { FAME }\end{array}$ & $\begin{array}{l}\text { Molecular } \\
\text { weight } M_{\text {FAME }} \\
(\mathrm{g} / \mathrm{mol})\end{array}$ & $\begin{array}{l}\text { Kinematic } \\
\text { viscosity } \mu \\
\left(\mathrm{mm}^{2} / \mathrm{s}\right)\end{array}$ & $\begin{array}{l}\text { High heating } \\
\text { value } \delta(\mathrm{MJ} / \\
\mathrm{kg})\end{array}$ & $\begin{array}{l}\text { Cetane number } \\
\mathrm{CN}\end{array}$ & $\begin{array}{l}\text { Carbon chain } \\
\text { length CL }\end{array}$ \\
\hline C4:0 & 102.13 & $0.36^{\mathrm{a}}$ & $28.98^{\mathrm{a}}$ & $16.38^{\mathrm{a}}$ & 4 \\
C6:0 & 130.18 & $0.68^{\mathrm{a}}$ & $32.63^{\mathrm{a}}$ & $28.34^{\mathrm{a}}$ & 6 \\
$\mathrm{C} 8: 0$ & 158.24 & 1.20 & 34.91 & 39.75 & 8 \\
$\mathrm{C} 18: 1$ & 296.49 & 4.51 & 40.09 & 59.30 & 18 \\
\hline
\end{tabular}

${ }^{\text {a}}$ Estimated using Eqs. (1-3)

for the calculation of reference values in this paper. However, the $\mu, \delta$, and $\mathrm{CN}$ of FAMEs with CLs of 4 and 6 could not be found in the literature. Therefore, these values had to be estimated using empirical models. The empirical equations [5] for the kinematic viscosity $\mu_{i}$, high heating value $\delta_{i}$, and cetane number $\mathrm{CN}_{i}$ reflect the dependence on molecular weight of individual saturated FAMEs $M_{i \mathrm{FAME}}$ as follows:

$$
\begin{gathered}
\ln \left(\mu_{i}\right)=a_{0}+b_{0} \ln \left(M_{i \mathrm{FAME}}\right), \\
\delta_{i}=c_{0}-d_{0} / M_{i \mathrm{FAME}}, \\
\mathrm{CN}_{i}=e_{0}+f_{0} M_{i \mathrm{FAME}} .
\end{gathered}
$$

To determine coefficients $a_{0}, b_{0}, c_{0}, d_{0}, e_{0}$ and $f_{0}$, the models (1-3) were applied to the data found in a previous work [25], which were measured according to biodiesel quality standards. Each data set $\left[\mu\left(M_{\mathrm{FAME}}\right), \delta\left(M_{\mathrm{FAME}}\right), \mathrm{CN}\left(M_{\mathrm{FAME}}\right)\right]$ was considered for saturated FAMEs with CLs from 8 to 18 . Then, the models were used to extrapolate the $\mu_{i}, \delta_{i}$, and $\mathrm{CN}_{i}$ values for FAMEs with CLs of 4 and 6 via Eqs. (1-3). All estimated values are also presented in Table 1.

The kinematic viscosities $\mu_{\text {mix }}$, heating values $\delta_{\text {mix }}$ and cetane numbers $\mathrm{CN}_{\text {mix }}$ of fatty acid mixture samples were estimated in terms of simple mixing rules $[5,26$, 27] via the following equations:

$$
\begin{gathered}
\ln \left(\mu_{\text {mix }}\right)=\sum_{i=1}^{n} A_{i} \ln \left(\mu_{i}\right), \\
\delta_{\text {mix }}=\sum_{i=1}^{n} A_{i} \delta_{i}, \\
\mathrm{CN}_{\text {mix }}=\sum_{i=1}^{n} A_{i} \mathrm{CN}_{i},
\end{gathered}
$$

where $A_{i}$ is the relative amount of an individual fatty acid in a mixture, $\mu_{i}$ is the kinematic viscosity, $\delta_{i}$ is the high heating value, and $\mathrm{CN}_{i}$ is the cetane number of an individual FAME corresponding to a fatty acid in a mixture. 
Calculation of the carbon chain length $\mathrm{CL}_{\text {mix }}$ was based on an approach explained in a previous paper [24]:

$$
\mathrm{CL}_{\text {mix }}=\sum_{i=1}^{n} a_{i} \mathrm{CL}_{i}
$$

where $a_{i}$ is the portion of $i$-acid molecules in the mixture, $n$ is the number of acids in the mixture, and $\mathrm{CL}_{\mathrm{i}}$ is the carbon chain length of $i$-acid.

Mixtures of hexanoic acid (Alfa Aesar, with a purity of $98 \%+$ ) and oleic acid (Alfa Aesar, with a purity of $90 \%$ ) were used for an online test realized by adding oleic acid $(C L=18)$ to hexanoic acid $(C L=6)$ in several steps. Pure samples of hexanoic and oleic acids were also measured.

\subsection{NMR measurements}

Online measurements of the molecular parameters for mixtures of two fatty acids were carried out using a TD-NMR system [28] that had been automated and modified for flowing samples [18]. The ${ }^{1} \mathrm{H}$ resonance frequency of the system was $26 \mathrm{MHz}$, and the temperature of the magnet was $30^{\circ} \mathrm{C}$.

The measurement procedure was as follows:

1. A sample was continuously mixed at room temperature $\left(25^{\circ} \mathrm{C}\right)$ in a container.

2. The sample was automatically pumped through the magnet system (tube diameter of $10 \mathrm{~mm}$ ).

3. When a new sample was being introduced to the system, the pump was stopped.

4. A transverse magnetization decay was measured and saved.

5. The decay was automatically fitted, and the NMR parameters were solved.

6. $R_{2}$ or $T_{2}$ values were used for $\mu, \delta, \mathrm{CN}$, and CL estimation.

7. The next sample was pumped.

Transverse magnetization decays were measured by applying the Carr-Purcell-Meiboom-Gill (CPMG) pulse sequence [29]. The echo time was $6 \mathrm{~ms}$, and the number of $180^{\circ}$ pulses in the sequence was 600 . The relaxation delay was $2 \mathrm{~s}$, and the number of scans was equal to 4 . The durations of $90^{\circ}$ and $180^{\circ} \mathrm{RF}$ pulses were 6.5 and $15 \mu$ s, respectively.

A Matlab software script written by the authors was used for controlling the pump and TD-NMR measurements, fitting the magnetization decays and calculating the molecular parameters based on linear models. Three different samples of each mixture (i.e., each CL) were pumped into the magnet system, and five measurements were performed for each sample. Thus, the total number of online measurements was 75.

\subsection{Data analysis}

NMR parameters in mono-exponential (8) and bi-exponential (9) functions were fitted to CPMG decays: 


$$
A(t)=A_{0} \mathrm{e}^{-R_{2} t}+a_{0},
$$

where $A_{0}$ is the maximal signal magnitude, $R_{2}$ is the spin-spin relaxation rate, and $a_{0}$ is the signal baseline, and

$$
A(t)=A_{1} \mathrm{e}^{-R_{21} t}+A_{2} \mathrm{e}^{-R_{22} t}+a_{0},
$$

where $A_{1}$ and $A_{2}$ are the magnitudes and $R_{21}$ and $R_{22}$ are the spin-spin relaxation rates of faster and slower decaying components, respectively, and $a_{0}$ is the signal baseline.

Spin-spin relaxation times, $T_{2}, T_{21}$, and $T_{22}$, were calculated as inverse values of the corresponding $R_{2}, R_{21}$, and $R_{22}$ as

$$
T_{2}=\frac{1}{R_{2}}
$$

Example fittings by the mono-exponential and bi-exponential functions of the transverse magnetization decay of a hexanoic and oleic acid mixture measured by the automated TD-NMR system are shown in Fig. 1.
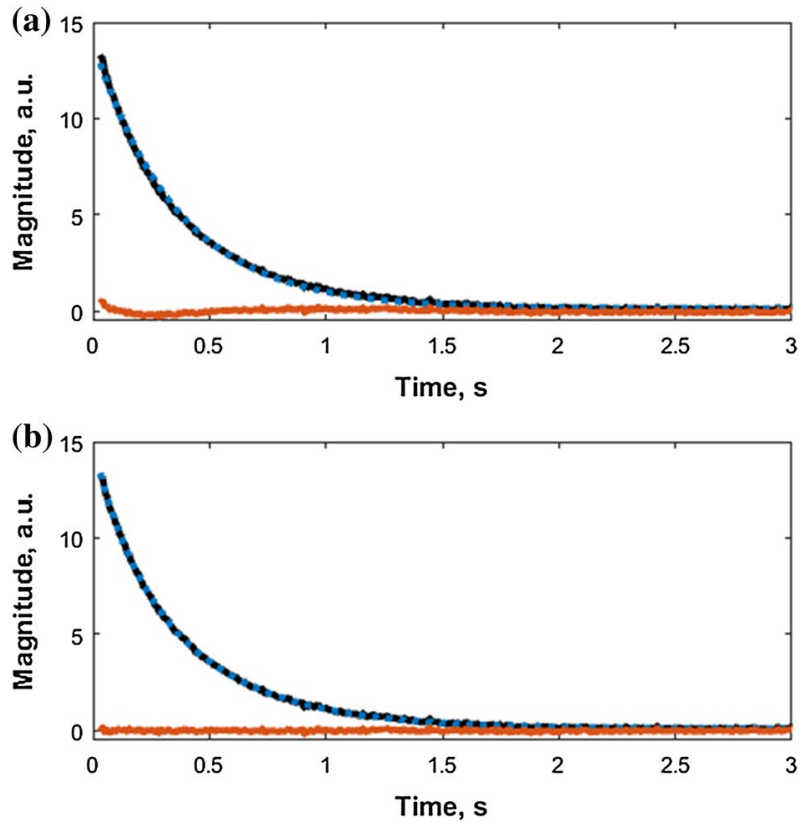

Fig. 1 Fittings by the mono-exponential (a) and bi-exponential (b) functions of the transverse magnetization decay of a hexanoic and oleic acid mixture $\left(\mathrm{CL}_{\text {mix }}=10.05\right)$. Decays are marked in black, fitting functions in blue and fitting errors in red 
Table 2 Average values of the spin-spin relaxation rates and RSE values from the mono- $\left(R_{2}\right)$ and bi$\left(R_{21}\right.$ and $R_{22}$ ) exponential fitting of the transverse magnetization decays of fatty acid mixtures measured in an online test

\begin{tabular}{lllllll}
\hline Mixture & $R_{2}^{\mathrm{a}}(1 / \mathrm{s})$ & RSE $(\%)$ & $R_{21}^{\mathrm{a}}(1 / \mathrm{s})$ & $\operatorname{RSE}(\%)$ & $R_{22}^{\mathrm{a}}(1 / \mathrm{s})$ & $\operatorname{RSE}(\%)$ \\
\hline 1 & 1.53 & 1.17 & 6.64 & 19.02 & 1.46 & 1.56 \\
2 & 2.14 & 1.78 & 6.32 & 13.84 & 1.94 & 3.52 \\
3 & 2.74 & 1.49 & 6.89 & 10.89 & 2.38 & 2.50 \\
4 & 3.41 & 1.30 & 8.05 & 7.86 & 2.91 & 2.67 \\
5 & 5.01 & 1.92 & 10.30 & 16.64 & 4.14 & 6.37 \\
& & $1.53^{\mathrm{b}}$ & & $13.65^{\mathrm{b}}$ & & $3.32^{\mathrm{b}}$ \\
\hline
\end{tabular}

${ }^{a}$ Averaged using three different samples that were measured five times

${ }^{\mathrm{b}}$ Average RSE value

Table 3 Kinematic viscosities $\mu_{\text {mix }}$, high heating values $\delta_{\text {mix }}$, cetane numbers $\mathrm{CN}_{\text {mix }}$, and carbon chain lengths $\mathrm{CL}_{\text {mix }}$ of fatty acid mixtures estimated by Eqs. (4-7)

\begin{tabular}{llllr}
\hline Mixture & $\mu_{\text {mix }}^{\mathrm{a}}\left(\mathrm{mm}^{2} / \mathrm{s}\right)$ & $\delta_{\text {mix }}^{\mathrm{a}}(\mathrm{MJ} / \mathrm{kg})$ & $\mathrm{CN}_{\text {mix }}^{\mathrm{a}}$ & $\mathrm{CL}_{\text {mix }}^{\mathrm{a}}$ \\
\hline 1 & 0.68 & 32.63 & 28.34 & 6.00 \\
2 & 1.27 & 35.10 & 38.59 & 8.03 \\
3 & 1.93 & 36.75 & 45.46 & 10.05 \\
4 & 2.61 & 37.94 & 50.39 & 12.05 \\
5 & 4.51 & 40.09 & 59.30 & 18.00 \\
\hline
\end{tabular}

${ }^{a}$ Averaged using three different samples that were measured five times

\section{Results}

The online test was performed by adding oleic acid to hexanoic acid in several steps and measuring the NMR relaxation values continuously. The NMR parameters in mono-exponential (8) and bi-exponential (9) functions were fitted to the measured transverse magnetization decays. The average values of the spin-spin relaxation rates, $R_{2}, R_{21}$, and $R_{22}$, and the corresponding relative standard errors (RSEs) calculated for each mixture are shown in Table 2. The RSEs for the monoexponential fitting show the smallest deviations.

The reference values of $\mu_{\text {mix }}, \delta_{\text {mix }}, \mathrm{CN}_{\text {mix }}$ and $\mathrm{CL}_{\text {mix }}$ for these mixtures are estimated by Eqs. (4-7) and are listed in Table 3. Using linear models, the correlation coefficients were calculated between the molecular properties $\left(\mu_{\text {mix }}, \delta_{\text {mix }}, \mathrm{CN}_{\text {mix }}\right.$, and $\left.\mathrm{CL}_{\text {mix }}\right)$ and NMR relaxation parameters $\left(R_{2}, T_{2}, \mathrm{R}_{21}, T_{21}, R_{22}\right.$, and $\left.T_{22}\right)$. The coefficients are listed in Table 4 and show better correlations with the relaxation rates in the cases of $\mu$ and CL and with the relaxation times in the cases of $\delta$ and CN. $R_{21}$ and $T_{21}$ did not give reliable correlations with the molecular properties.

The molecular properties $\mu_{\mathrm{NMR}}, \delta_{\mathrm{NMR}}, \mathrm{CN}_{\mathrm{NMR}}$, and $\mathrm{CL}_{\mathrm{NMR}}$ were derived from measured NMR relaxation data using linear models with $R_{2}$ or $T_{2}$ and $R_{22}$ or $T_{22}$. The average RSEs for estimated values of $\mu_{\mathrm{NMR}}, \delta_{\mathrm{NMR}}, \mathrm{CN}_{\mathrm{NMR}}$, and $\mathrm{CL}_{\mathrm{NMR}}$ are presented in Table 5. The NMR relaxation data obtained from the 
Table 4 Correlation coefficients between the molecular properties $\mu_{\text {mix }}, \delta_{\text {mix }}, \mathrm{CN}_{\text {mix }}$ and $\mathrm{CL}_{\text {mix }}$ estimated by Eqs. (4-7) and the spin-spin relaxation rates and times

\begin{tabular}{llrrrr}
\hline Model & NMR parameter & \multicolumn{1}{c}{$\mu_{\text {mix }}$} & \multicolumn{1}{c}{$\delta_{\text {mix }}$} & \multicolumn{1}{c}{$\mathrm{CN}_{\text {mix }}$} & \multicolumn{1}{c}{$\mathrm{CL}_{\text {mix }}$} \\
\hline Mono-exponential & $R_{2}$ & $\mathbf{0 . 9 9 8}$ & 0.966 & 0.966 & $\mathbf{0 . 9 9 8}$ \\
Mono-exponential & $T_{2}$ & -0.917 & $\mathbf{- 0 . 9 9 3}$ & $\mathbf{- 0 . 9 9 3}$ & -0.920 \\
Bi-exponential & $R_{21}$ & 0.759 & 0.672 & 0.672 & 0.756 \\
Bi-exponential & $T_{21}$ & -0.695 & -0.646 & -0.646 & -0.692 \\
Bi-exponential & $R_{22}$ & $\mathbf{0 . 9 9 1}$ & 0.958 & 0.958 & $\mathbf{0 . 9 9 1}$ \\
Bi-exponential & $T_{22}$ & -0.931 & $\mathbf{- 0 . 9 9 4}$ & $\mathbf{- 0 . 9 9 4}$ & -0.934 \\
\hline
\end{tabular}

The best correlations are marked in bold

Table 5 Average RSE values for the molecular properties $\mu_{\mathrm{NMR}}, \delta_{\mathrm{NMR}}, \mathrm{CN}_{\mathrm{NMR}}$, and $\mathrm{CL}_{\mathrm{NMR}}$ calculated using the NMR parameters from the mono- $\left(R_{2}\right.$ or $\left.T_{2}\right)$ and bi- $\left(R_{22}\right.$ or $\left.T_{22}\right)$ exponential fits

\begin{tabular}{llllll}
\hline Model & NMR parameter & $\begin{array}{l}\mu_{\mathrm{NMR}} \\
\mathrm{RSE}(\%)\end{array}$ & $\begin{array}{l}\delta_{\mathrm{NMR}} \\
\mathrm{RSE}(\%)\end{array}$ & $\begin{array}{l}\mathrm{CN}_{\mathrm{NMR}} \\
\mathrm{RSE}(\%)\end{array}$ & $\begin{array}{l}\mathrm{CL}_{\mathrm{NMR}} \\
\operatorname{RSE}(\%)\end{array}$ \\
\hline Mono-exponential & $R_{2}$ & 2.61 & - & - & 1.44 \\
Mono-exponential & $T_{2}$ & - & 0.26 & 1.01 & - \\
Bi-exponential & $R_{22}$ & 6.00 & - & - & 3.52 \\
Bi-exponential & $T_{22}$ & - & 0.59 & 2.12 & - \\
\hline
\end{tabular}

mono-exponential fittings provide the smallest deviations in the estimations of molecular properties (Table 5). These fittings correspond to the best correlation coefficients, which were acquired between $\mu_{\text {mix }}, \delta_{\text {mix }}, \mathrm{CN}_{\text {mix }}$, and $\mathrm{CL}_{\text {mix }}$ and $R_{2}$ or $T_{2}$ and were equal to $0.998,-0.993,-0.993$, and 0.998 , respectively (Table 4). The molecular properties estimated by the linear models for all 75 measurement points in the online test are shown in Fig. 2a-d. The average RSEs between the reference values and the values determined by TD-NMR for $\mu, \delta, \mathrm{CN}$, and CL were $2.4,0.5,2.0$, and $0.9 \%$, respectively.

\section{Discussion}

In the current paper, the possibility of using TD-NMR for the rapid and simultaneous estimation of four quality parameters of liquid fuels- $\mu, \delta, \mathrm{CN}$, and CL-was demonstrated. An online determination of these parameters was shown using an automated TD-NMR system modified for flowing samples. The results show a very good agreement between the reference and NMR-determined values.

Mono- and bi-exponential fittings were applied to the data set from the online test, where faster (minor) and slower (major) decaying components were observed (Fig. 1). The average RSE for $R_{2}$ from the mono-exponential fitting was $1.53 \%$, whereas the average RSEs for $R_{21}$ and $R_{22}$ from the bi-exponential fitting were 13.65 and $3.32 \%$, respectively (Table 3 ). The higher deviations of $R_{21}$ and $R_{22}$ could have been caused by poor stability of the bi-exponential fitting procedure. Moreover, the 

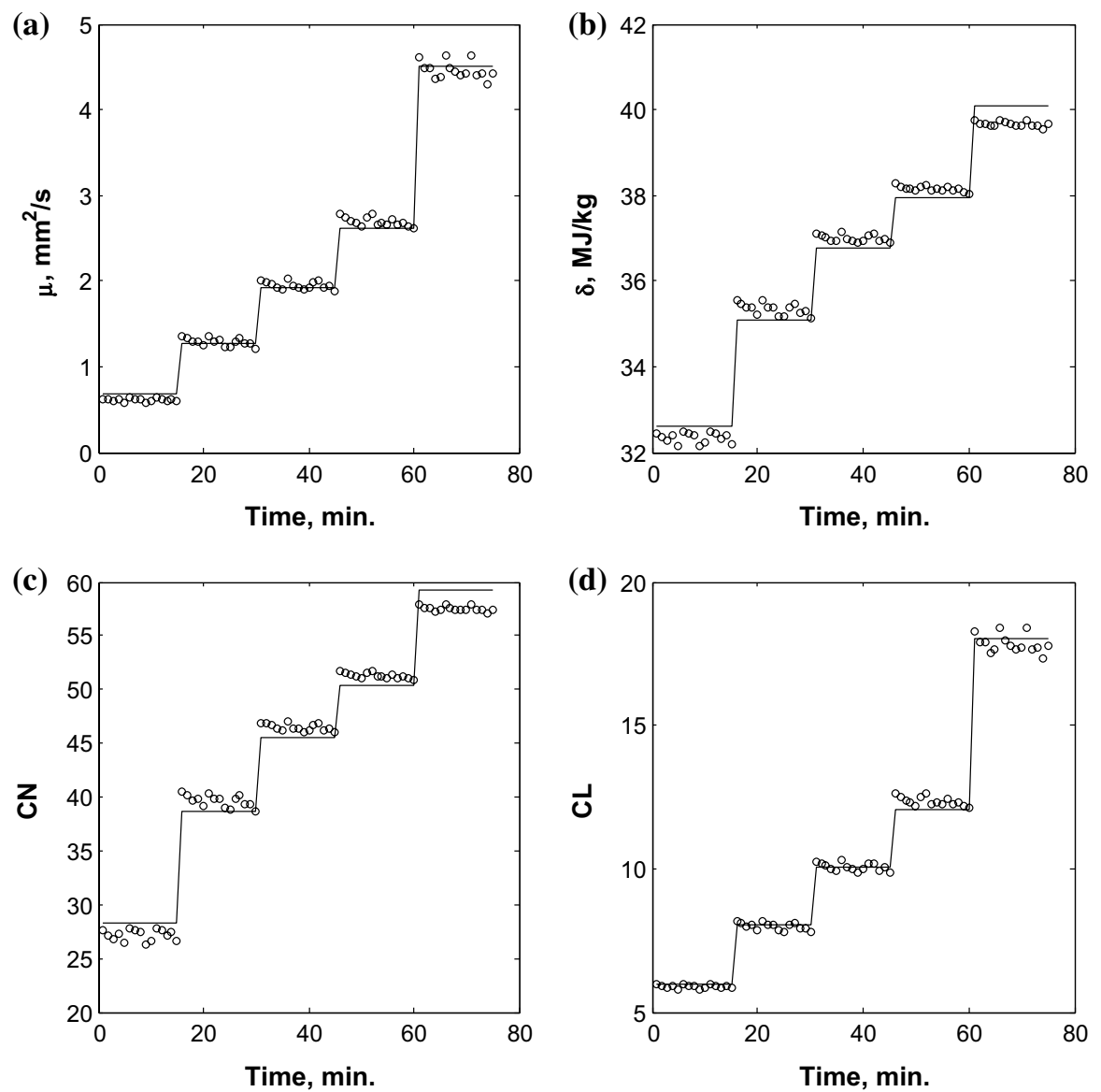

Fig. 2 Online determination of the kinematic viscosity $\mu_{\mathrm{NMR}}(\mathbf{a})$, high heating value $\delta_{\mathrm{NMR}}(\mathbf{b})$, cetane number $\mathrm{CN}_{\mathrm{NMR}}(\mathbf{c})$, and carbon chain length $\mathrm{CL}_{\mathrm{NMR}}(\mathbf{d})$. The solid lines denote the reference values $\mu_{\text {mix }}$, $\delta_{\text {mix }}, \mathrm{CN}_{\text {mix }}$, and $\mathrm{CL}_{\text {mix }}$

average RSEs of the molecular properties $\mu_{\mathrm{NMR}}, \delta_{\mathrm{NMR}}, \mathrm{CN}_{\mathrm{NMR}}$, and $\mathrm{CL}_{\mathrm{NMR}}$ calculated using $R_{22}$ or $T_{22}$ values were more than two times larger than those calculated using the mono-exponentially fitted $R_{2}$ or $T_{2}$ (Table 5). Although the $R_{22}$ and $T_{22}$ values presented similar correlations with the molecular properties as the $R_{2}$ or $T_{2}$ values (Table 4), mono-exponential fitting provided less deviation in the $R_{2}$ and $T_{2}$ values as well as in the calculated values of $\mu_{\mathrm{NMR}}, \delta_{\mathrm{NMR}}, \mathrm{CN}_{\mathrm{NMR}}$, and $\mathrm{CL}_{\mathrm{NMR}}$. Therefore, the mono-exponential fitting was a more robust approach and thus was used to calculate the quality parameters. In addition, the corresponding values of $R_{2}$ and $T_{2}$ reflect the mean values of faster and slower decaying signal components.

The presence of two components in transverse magnetization decays can arise from the contribution of the spin-spin relaxation of protons with different mobilities. Impurities $(10 \%)$ present in the oleic acid used may have also been responsible 
for the faster decaying component. In the previous works [30, 31], the presence of two components in the transverse magnetization decays of oleic acid and the methyl ester of oleic acid was connected to the different mobilities of protons on the carbon chain. However, in our earlier paper [24], magnetization decays measured for mixtures of different fatty acids showed only one peak in the Laplace transformation.

The molecular properties $\mu_{\mathrm{NMR}}, \delta_{\mathrm{NMR}}, \mathrm{CN}_{\mathrm{NMR}}$, and $\mathrm{CL}_{\mathrm{NMR}}$ calculated from single $R_{2}$ or $T_{2}$ values and the reference values $\mu_{\text {mix }}, \delta_{\text {mix }}, \mathrm{CN}_{\text {mix }}$, and $\mathrm{CL}_{\text {mix }}$ for all measured points are shown in Fig. 2. The average RSEs between the reference and TDNMR values did not exceed $2.4 \%$, so the application of this online test to industrial quality control is promising. The acquired results are in good agreement with the results of the previous investigations [20], where several quality parameters of petroleum fractions correlated with $R_{2}$ or $\ln T_{2}$. These authors also used the major peak of the inverse Laplace distribution of the transverse magnetization decays of petroleum fractions to correlate the NMR values with quality parameters, while the minor peak in the distribution was considered an artefact and neglected. In another paper [14], both a univariate approach and multivariate approach (using PLS) gave good correlations of the transverse relaxation parameters with the biodiesel content in biodiesel-diesel blends. Although the Laplace distribution of a pure biodiesel sample revealed two peaks, only the major peak was associated with the biodiesel content in mixtures with diesel.

It has been previously shown [24] that TD-NMR can be used to determine the CLs of fatty acid mixtures, which is an important quality parameter of liquid fuels. In addition, this relationship was briefly confirmed by NMR relaxation theory. The values $R_{2}$ and $T_{2}$ from a previous paper [24] were also used in the current paper to prove the validity of the presented approach for estimation of $\mu, \delta$, and CN. Linear relationships were obtained between $R_{2}$ or $T_{2}$ [24] and the reference values $\mu_{\text {mix }}$, $\delta_{\text {mix }}$ and $\mathrm{CN}_{\text {mix }}$ calculated by Eqs. (4-6) using data from Table 1. The molecular properties $\mu_{\text {mix }}, \delta_{\text {mix }}$, and $\mathrm{CN}_{\text {mix }}$ as functions of the relaxation rate $R_{2}$ or time $T_{2}$ are shown in Fig. 3a-c. The good correlations between the spin-spin relaxation times $T_{2}$ or rates $R_{2}$ and these parameters suggest that the TD-NMR method can be used to evaluate fuel quality more generally.

Several research groups [17, 32-35] have shown the use of an NMR technique in a flow mode. Measurements of flowing samples require pre-magnetization of the ${ }^{1} \mathrm{H}$ nucleus in a magnet system for a time of $5 T_{1}$ [11]. The dimensions of the NMR probe and magnet system should be appropriate for providing uniform sample excitation and acquisition as well as initial pre-magnetization. On the other hand, measurements for non-equilibrium magnetization can be done [36], which makes a device simpler. In addition, the flow rate should be constant in both cases. For example, the NMR relaxation times of fluids were measured under continuous flow with a maximal detectable flow velocity of approximately $30 \mathrm{~mm} / \mathrm{s}$ by low-field NMR fluid analysis systems [33-35]. Reactions can also be monitored using an NMR spectrometer equipped with a flow cell in a bypass with a lower velocity (not exceeding $2 \mathrm{~mL} / \mathrm{min}$ ) than that in the main reactor [11, 17, 32]. However, the flow velocities in the real industrial processes are typically very high (on the order of $\mathrm{m} / \mathrm{s}$ ). In most cases, the process measurements were made during stopped flow $[18,35]$ or in a bypass with a low flow velocity [11, 
Fig. 3 Kinematic viscosity $\mu_{\text {mix }}$ plotted as a function of the relaxation rate $R_{2}(\mathbf{a})$. High heating value $\delta_{\text {mix }}$ and cetane number $\mathrm{CN}_{\text {mix }}$ plotted as functions of the relaxation time $T_{2}$ $(\mathbf{b}, \mathbf{c})$. The solid lines are fitted by linear models
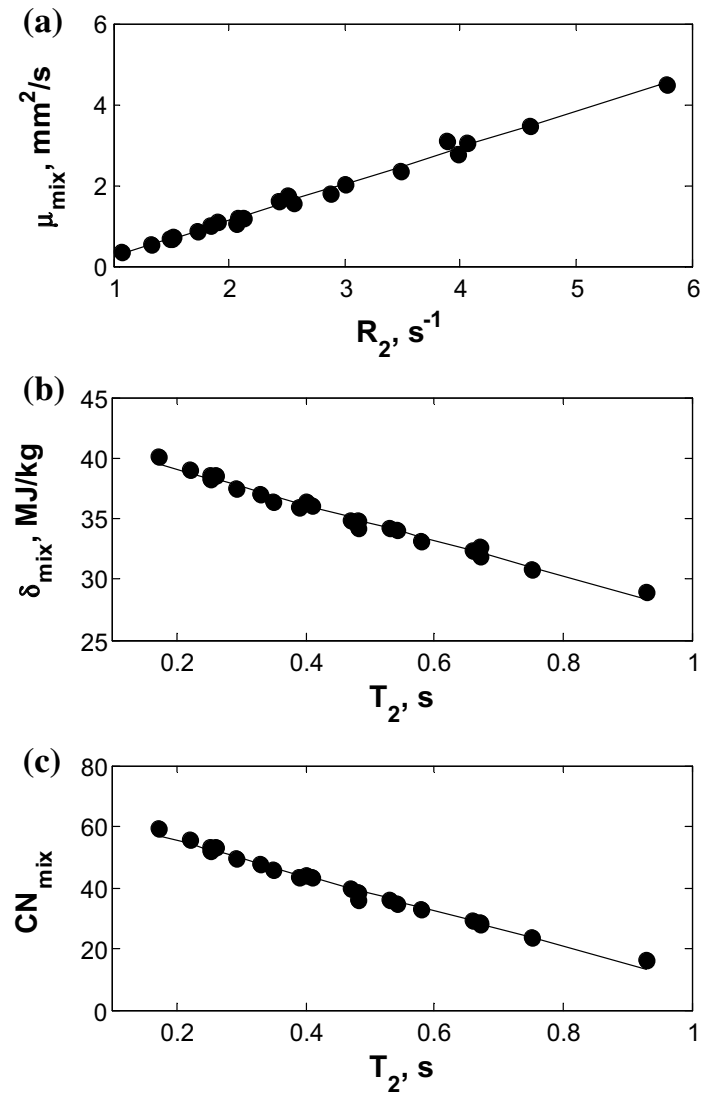

17, 32]. Therefore, methods consisting of sample measurements during stopped flow appear to be applicable for real process monitoring, although the sampling of stopped flow can be more time-consuming compared to continuous flow.

The reliability of measurements made by TD-NMR systems was checked. The difference between the $R_{2}$ values measured by the conventional NMR relaxometer and by the system modified for flowing samples was less than $1.4 \%$ for the same chemical. To estimate the accuracy of the online TD-NMR test performed, the RSEs of the $R_{2}$ values were calculated for each mixture of three individual samples. The average RSE calculated for all mixtures was equal to $0.6 \%$, and the corresponding value for the same samples measured conventionally in NMR tubes was $0.5 \%$. These results confirm that, for homogeneous liquid samples, the TDNMR system modified for flowing samples provided the same order of measurement accuracy as the conventional device.

Low-field NMR systems with permanent magnets are increasingly being used for quantitative analysis in quality control, as well as for online instruments in production environments [11]. The feasibility of using TD-NMR for the online analytics of mine water has also been shown [18], and the method was tested in 
a real mine, which is a very challenging environment for these kinds of measurements. The online tests in this paper yielded promising results for developing online applications based on TD-NMR. Moreover, a single TD-NMR measurement can provide valuable information on the quality of liquid fuels. This technique offers robust, rapid, and non-destructive sample analysis, characteristics that are very important for industrial process control.

\section{Conclusion}

The results presented herein illustrate a general dependence between the molecular properties of fatty acid mixtures and NMR parameters, showing that TD-NMR can be used for the rapid and simultaneous determination of several quality parameters of liquid fuels. These online measurements demonstrate the potential of TD-NMR technology for online quality control during the production of liquid fuels.

Open Access This article is distributed under the terms of the Creative Commons Attribution 4.0 International License (http://creativecommons.org/licenses/by/4.0/), which permits unrestricted use, distribution, and reproduction in any medium, provided you give appropriate credit to the original author(s) and the source, provide a link to the Creative Commons license, and indicate if changes were made.

\section{References}

1. J.G. Speight, Handbook of Petroleum Product Analysis (Wiley, Hoboken, 2002)

2. G. Knothe, Fuel Process. Technol. 86, 1059-1070 (2005). https://doi.org/10.1016/j.fupro c.2004.11.002

3. V.M. Mello, F.C.C. Oliveira, W.G. Fraga, C.J. do Nascimento, P.A.Z. Suarez, Magn. Reson. Chem. 46, 1051-1054 (2008). https://doi.org/10.1002/mrc.2282

4. E.J. Lohman, R.D. Gardner, L. Halverson, R.E. Macur, B.M. Peyton, R. Gerlach, J. Microbiol. Methods 94, 235-244 (2013). https://doi.org/10.1016/j.mimet.2013.06.007

5. L.F. Ramírez-Verduzco, J.E. Rodríguez-Rodríguez, A.R. del Rayo Jaramillo-Jacob, Fuel 91, 102111 (2012). https://doi.org/10.1016/j.fuel.2011.06.070

6. M. ter Horst, S. Urbin, R. Burton, C. MacMillan, Lipid Technol. 21(2), 1-3 (2009). https://doi. org/10.1002/lite.200900004

7. M.R. Monteiro, A.R.P. Ambrozin, L.M. Lião, E.F. Boffo, E.R. Pereira-Filho, A.G. Ferreira, J. Am. Oil Chem. Soc. 86, 581-585 (2009). https://doi.org/10.1007/s11746-009-1374-7

8. M.R. Monteiro, A.R.P. Ambrozin, M. da Silva Santos, E.F. Boffo, E.R. Pereira-Filho, L.M. Lião, A.G. Ferreira, Talanta 78, 660-664 (2009). https://doi.org/10.1016/j.talanta.2008.12.026

9. B. Diehl, G. Randel, Lipid Technol. 19(11), 258-260 (2007). https://doi.org/10.1002/lite.200700087

10. C.R. Souza, A.H. Silva, N. Nagata, J.L.T. Ribas, F. Simonelli, A. Barison, Energy Fuels 28, 49584962 (2014). https://doi.org/10.1021/ef501000a

11. F. Dalitz, M. Cudaj, M. Maiwald, G. Guthausen, Prog. Nucl. Magn. Reson. Spectrosc. 60, 52-70 (2012). https://doi.org/10.1016/j.pnmrs.2011.11.003

12. K. Singh, B. Blümich, Trends Anal. Chem. 83, 12-26 (2016). https://doi.org/10.1016/j. trac.2016.02.014

13. M.H.M. Killner, E. Danieli, F. Casanova, J.J.R. Rohwedder, B. Blümich, Fuel 203, 171-178 (2017). https://doi.org/10.1016/j.fuel.2017.04.081

14. G. da Rocha, L.A. Colnago, T.B. Moraes, G.F. Zagonel, G.I. Bolzon de Muniz, P.G. PeraltaZamora, A. Barison, Energy Fuels 31(5), 5120-5125 (2017). https://doi.org/10.1021/acs.energyfuel s.6b03508 
15. J. Mitchell, L.F. Gladden, T.C. Chandrasekera, E.J. Fordham, Prog. Nucl. Magn. Reson. Spectrosc. 76, 1-60 (2014). https://doi.org/10.1016/j.pnmrs.2013.09.001

16. B. Blümich, F. Casanova, S. Appelt, Chem. Phys. Lett. 477, 231-240 (2009). https://doi. org/10.1016/j.cplett.2009.06.096

17. M. Maiwald, H.H. Fischer, Y.-K. Kim, K. Albert, H. Hasse, J. Magn. Reson. 166, 135-146 (2004). https://doi.org/10.1016/j.jmr.2003.09.003

18. E. Nikolskaya, M. Liukkonen, J. Kankkunen, Y. Hiltunen, IFAC-PapersOnLine 48-17, 098-101 (2015). https://doi.org/10.1016/j.ifacol.2015.10.085

19. P.M. Santos, R.S. Amais, L.A. Colnago, A. Rinnan, M.R. Monteiro, Energy Fuels 29, 2299-2303 (2015). https://doi.org/10.1021/acs.energyfuels.5b00017

20. L.L. Barbosa, F.V.C. Kock, R.C. Silva, J.C.C. Freitas, V. Lacerda Jr., E.V.R. Castro, Energy Fuels 27, 673-679 (2013). https://doi.org/10.1021/ef301588r

21. L.L. Barbosa, C.M.S. Sad, V.G. Morgan, P.R. Figueiras, E.R.V. Castro, Fuel 176, 146-152 (2016). https://doi.org/10.1016/j.fuel.2016.02.085

22. R.A. Prestes, L.A. Colnago, L.A. Forato, L. Vizzotto, E.H. Novotny, E. Carrilho, Anal. Chim. Acta 596, 325-329 (2007). https://doi.org/10.1016/j.aca.2007.06.022

23. L.F. Cabeça, L.V. Marconcini, G.P. Mambrini, R.B.V. Azeredo, L.A. Colnago, Energy Fuels 25(6), 2696-2701 (2011). https://doi.org/10.1021/ef200294j

24. E. Nikolskaya, Y. Hiltunen, Appl. Magn. Reson. 49, 185-193 (2018). https://doi.org/10.1007/s0072 3-017-0953-2

25. G. Knothe, Energy Fuels 22, 1358-1364 (2008). https://doi.org/10.1021/ef700639e

26. G. Knothe, Fuel Prop. 26, 5265-5273 (2012). https://doi.org/10.1021/ef300700v

27. C.A.W. Allen, K.C. Watts, R.G. Ackman, M.J. Pegg, Fuel 78, 1319-1326 (1999). https://doi. org/10.1016/S0016-2361(99)00059-9

28. Resonance Systems Ltd, http://www.nmr-design.com Accessed 23 Oct 2017

29. A. Abragam, The Principles of Nuclear Magnetism (Clarendon Press, Oxford, 1961)

30. P. Berman, N. Meiri, L.A. Colnago, T.B. Moraes, C. Linder, O. Levi, Y. Parmet, M. Saunders, Z. Wiesman, Biotechnol. Biofuels 8, 12 (2015). https://doi.org/10.1186/s13068-014-0194-7

31. N. Meiri, P. Berman, L.A. Colnago, T.B. Moraes, C. Linder, Z. Wiesman, Biotechnol. Biofuels 8, 96 (2015). https://doi.org/10.1186/s13068-015-0280-5

32. A. Michalik-Onichimowska, S. Kern, J. Riedel, U. Panne, R. King, M. Maiwald, J. Magn. Reson. 277, 154-161 (2017). https://doi.org/10.1016/j.jmr.2017.02.018

33. F. Deng, L. Xiao, M. Wang, Y. Tao, L. Kong, X. Zhang, X. Liu, D. Geng, Appl. Magn. Reson. 47, 1239-1253 (2016). https://doi.org/10.1007/s00723-016-0832-2

34. H. Herold, E.H. Hardy, M. Ranft, K.-H. Wassmer, N. Nestle, Microporous Mesoporous Mater. 178, 74-78 (2013). https://doi.org/10.1016/j.micromeso.2013.03.001

35. M.K. Sørensen, M.S. Vinding, O.N. Bakharev, T. Nesgaard, O. Jensen, N.C. Nielsen, Anal. Chem. 86, 7205-7208 (2014). https://doi.org/10.1021/ac5014496

36. F. Dalitz, L. Kreckel, M. Maiwald, G. Guthausen, Appl. Magn. Reson. 45, 411-425 (2014). https:// doi.org/10.1007/s00723-014-0522-X 